\title{
Anophthalmia and serious microphthalmia: a summary of the problems associated with antenatal diagnosis and therapeutic refunding in Sub-Saharan Africa
}

\author{
This article was published in the following Dove Press journal: \\ International Medical Case Reports Journal \\ 4 November 2015 \\ Number of times this article has been viewed
}

\author{
Ibrahim Abib Diomande' \\ Abdoulaye Toure ${ }^{2}$ \\ Konan Virgile Koffi' \\ Gossé François Diomande' \\ Windinmanégdé Pierre \\ Djiguimde ${ }^{3}$ \\ Nouraly Habib ${ }^{4}$ \\ Ahgbatouhabéba Ahnoux- \\ Zabsonre ${ }^{3}$ \\ 'Ophthalmology Department, Center \\ Hospital University of Bouaké, \\ University Alassane Ouattara, \\ ${ }^{2}$ Radiology Department, Center \\ Hospital University of Yopougon, \\ University Félix Houphouët Boigny, \\ Côte d'Ivoire; ${ }^{3}$ Ophthalmology \\ Department, Center Hospital \\ University Yalgado Ouédraogo, \\ Ouagadougou, Burkina Faso; \\ ${ }^{4}$ Radiology Department, Center \\ Hospital University of Mahavoky \\ Atsimo, Mahajanga, Madagascar
}

Correspondence: Ibrahim Abib

Diomande

Ophthalmology Department, University

Hospital of Bouaké, University

Alassane Ouattara, 0I Bp I I74

Bouake 0I, Côte d'Ivoire

Email abib.diomande@doctor.com

\begin{abstract}
Anophthalmia and serious microphthalmia are conditions characterized by the complete lack of the primary optic vesicle or the presence of the rudimentary eye-like structure. These are rare prenatal conditions, yet diagnoses remain a challenge in Black African areas, raising a major concerns surrounding care after birth. This paper reports a case of anophthalmia and serious microphthalmia, the diagnosis of which was not possible despite many ultrasounds undergone by the mother during pregnancy.
\end{abstract}

Keywords: pediatric, malformation, antenatal diagnosis, treatment, Africa

\section{Introduction}

Anophthalmia and serious microphthalmia are a rare congenital malformations, affecting approximately $0.6 / 10,000$ live births. ${ }^{1,2}$ These conditions are sometimes associated with other abnormalities affecting certain parts of the body such as the limbs, brain, cardiovascular, renal, and pulmonary systems, resulting in various comorbidities. ${ }^{3}$

The objectives of this work were to highlight the difficulties associated with the antenatal diagnosis of a severe case of anophthalmia and microphthalmia, as well as to investigate the complexity of psychological and therapeutical refunding of these congenital conditions in Sub-Saharan Africa.

\section{Observation}

A 3-day-old newborn male presented with eyelid malformation. The staff at the Neonatology Department of Pediatrics in the Center Hospital University, Bouaké, Côte d'Ivoire, attended the patient.

The patient's mother, a resident of Bouaké, was 30 years old, with gravidity 4 and parity 2 (including a spontaneous abortion at 17 weeks). During the pregnancy, routine serological testing determined that she had sickle cell disease (type AS, $\mathrm{S}=79 \%$ ), a rubella titer of $13 \mathrm{IU} / \mathrm{mL}$, a toxoplasmosis $\mathrm{IgG}$ titer of $14 \mathrm{IU} / \mathrm{mL}$, and that she was syphilis (Treponema pallidum haemagglutination [TPHA], venereal disease research laboratory [VDRL])-negative, hepatitis B- and C-negative, and HIV-negative. The mother had health insurance that allowed for nine prenatal consultations with accompanying obstetric ultrasounds. The radiologist reported no abnormalities during this time. The mother did not take any medication or drugs, and was not exposed to teratogens, toxins, or abnormal levels of radiation during the pregnancy. Moreover, no congenital abnormalities were noted. 
After a gestational period of 39 weeks, the patient was delivered via cesarean section. The birth weight was recorded as $3,750 \mathrm{~g}$, with a head circumference of $33 \mathrm{~cm}$, and a height of $51 \mathrm{~cm}$. The patient's Apgar score was 8 at 1 minute, and 9 at 5 minutes after birth. He had a healthy pigmentation and demonstrated a good sucking instinct. The discovery of a bilateral palpebral occlusion coupled with the observation that he did not appear to have eyeballs, prompted the patient's transfer to the Ophthalmology Department of the Center Hospital University. A subsequent examination revealed a slight bilateral introversio of the eyelid (entropion), with fine eyelids and little palpebral fissures (Figure 1). Spacing the eyelids with a pediatric speculum showed an emptiness of the orbital cavities which were reduced. An emergency clinical assessment (including cardiovascular, pulmonary pleura, genitourinary, and neurological tests) was requested. Paraclinical testing, comprising cerebral magnetic resonance imaging (MRI); an orbital frontal brain scan; an ocular ultrasound; and thoracoabdominal, face, and chest radiography; was carried out to search for associated congenital malformations. MRI and the patient's karyotype could not be ascertained due to lack of equipment. The ocular ultrasound (Figure 2), as well as the orbital brain CT scan (Figure 3), showed severe right-side microphthalmia (presence of an optic vesicle filling the orbital cavity, with a visible optic nerve and rectus muscles), and associated left eye anophthalmia (empty orbital cavity).

\section{Ethics statement}

This case report followed the tenets of the Declaration of Helsinki and was approved by the Center Hospital University of Bouake. Consent was obtained from the parents of the newborn.

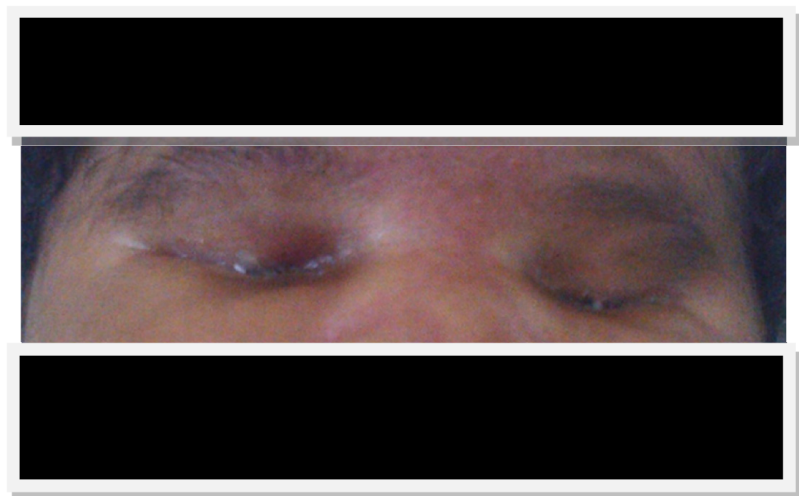

Figure I Orbital depression due to orbital cavity emptiness in a newborn with severe right microphthalmia and left anophthalmia.

\section{Discussion}

The exact pathogenesis of severe anophthalmia and microphthalmia is not well understood. According to some authors, it would be about a fail of the normal development of the neural tube at the beginning of the gestation. ${ }^{4}$ Chromosomal genetic factors such as (number, structure, duplication, deletion), and environmental factors such as (pesticides, gestational-acquired infections, vitamin deficiency, alcohol) would be involved in the occurrence of this malformation and also lead to some syndromes. ${ }^{5,6}$ Genetic counseling may be difficult in view of the large number of genes implicated and phenotypic variability. This genetic counseling indicated only when the mode of transmission was identified. Until now, only the SOX2 gene (located on chromosome 11q13) has been identified as being a major gene in the occurrence of anophthalmia and severe microphthalmia. ${ }^{5}$ The diagnosis is generally based on clinical criteria and imaging results. Such testing permits the involvement of a multidisciplinary team composed of ophthalmologists, clinical geneticists, radiologists and, in the case of a young patient. The anophthalmia can potentially be a clinical diagnosis, difficult to do as it puts to confusion with the severe microphthalmia. ${ }^{7}$

Minor microphthalmia is generally diagnosed during the clinical examination by inspection and palpation of the eye through the eyelids. For the patient in the current study, diagnosis of his severe microphthalmia was only possible with an ocular ultrasound and the orbital brain CT scan postnatal, both of which confirmed the presence of an optic vesicle in the right orbit. This was subsequently recognized as being a severe form of microphthalmia, and the final diagnosis was based on the literature. ${ }^{7}$

The patient's mother had the benefit of monthly ultrasounds throughout the entire pregnancy, during which time, anophthalmia and microphthalmia of the fetus was not diagnosed. This fact highlights the limitations of current paraclinical testing in African countries, especially when considering the challenges associated with radiology-based antenatal diagnosis of pathologies such as a severe anophthalmia and microphthalmia. Furthermore, African hospitals generally employ radiologists who are not specialized in the diagnosis and monitoring of maternal and fetal abnormalities. The radiologists' major objective during the monitoring of pregnancy is the provision of at least three ultrasound examinations (one ultrasound examination/quarter) to check for certain characteristics or anomalies. Fetal vitality, associated gynecological pathologies, fetal organ abnormalities, fetal malformations, placental morphology, bead appearance, and level of amniotic fluid are routinely checked by radiologists and are considered in relation to gestational age. ${ }^{8}$ 


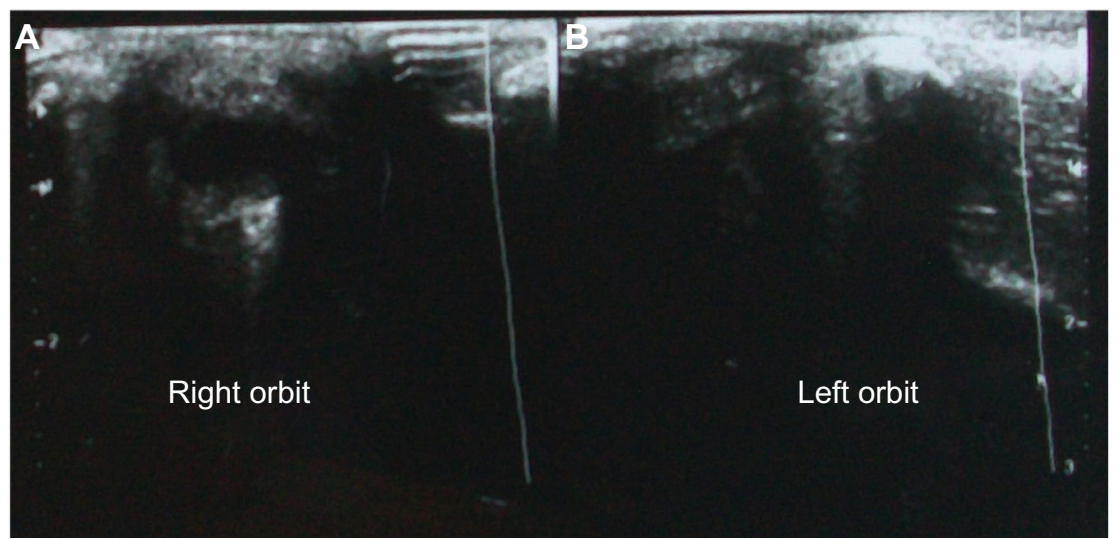

Figure 2 Ocular ultrasound of a newborn affected by (A) severe right-side microphthalmia with the presence of a vesicle in the right-side cavity, and (B) left-side anophthalmia with an empty orbital cavity.

Roth et $\mathrm{al}^{7}$ carried on anophthalmia and showed interest of the bi-dimensional ultrasound and experience of the radiologists in the prenatal diagnosis of anophtalmiaand microphthalmia. Some studies have reported the possibility of antenatal diagnosis using regular endovaginal ultrasounds, commencing from the 12 th week of amenorrhea. ${ }^{9-11}$

In addition to emphasizing the shortcomings of paraclinical testing to prenatally diagnose anophthalmia and microphthalmia, the current study also confirms the limitations of prenatal ultrasound diagnoses of other defects, including malformations of the face. Araujo Júnior et $\mathrm{al}^{1}$ pointed out the potential of 3D and the MRI. The same observation was made by Wong et al, ${ }^{12}$ who showed that $3 \mathrm{D}$ ultrasound examinations could identify facial and orbital abnormalities in the fetus, even when the fetal head was in a bad position for diagnosis in 2D imaging.

The challenges encountered in medical facilities throughout Sub-Saharan Africa are linked to poverty, with the lack of technical equipment making the diagnoses of many pathologists a difficult task. Indeed, the cost of imaging equipment and the financial insecurity of many patients mean that Sub-
Saharan African radiologists rarely perform 3D ultrasounds. Despite these difficulties, these authors ${ }^{1,7,9,10,11}$ confirm the possibility of a prenatal diagnosis of severe anophthalmia and microphthalmia. This diagnosis is made possible through complete complementary examinations for the precise identification of the stage and prognoses of malformations. ${ }^{13}$ Such a diagnosis would serve to evaluate, to inform, and to propose a therapeutic interruption of pregnancy to parents. This is an extremely difficult decision but is sometimes desirable in the view of the functional and aesthetic prejudices of the new born with anophthalmia or serious microphthalmia. This decision would be preferable because functional and aesthetic results of anophthalmia and serious microphthalmia are sometimes disappointing despite many difficult surgical treatments. ${ }^{14}$ The option of interrupting the pregnancy would be discussed in the event of bilateral severe anophthalmia and serious microphthalmia, especially in Black African countries where poverty is rife, and health insurance is inexistent for the majority of the population. Consequently, there is little medical coverage for newborns with anophthalmia and/or microphthalmia, and the psychosocial states of parents in

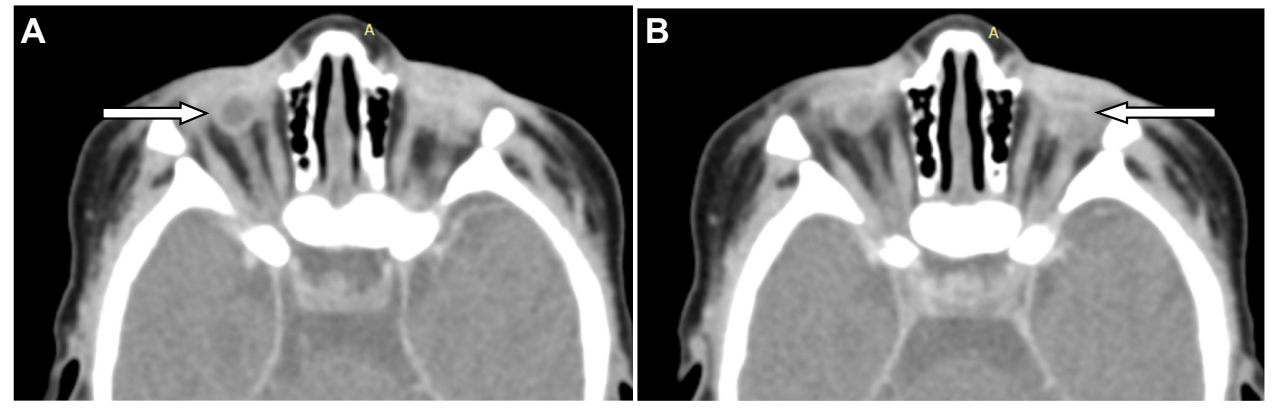

Figure 3 Axial section of ocular CT scan in parenchymal window after contrast injection.

Notes: (A) Right side microphthalmia; notice that the lens is absent, the optic nerve, the internal and external rectus muscles are present (arrow). (B) Left side anophthalmia; notice that there are no eye and no optic nerve. Internal and external rectus muscles are fixed in one place (arrow).

Abbreviation: computed tomography. 
such a situation are complex. ${ }^{15}$ The lack of adequate facilities in Sub-Saharan Africa, as well as the lack of materials for ocular prostheses, exposes children affected by severe anophthalmia or microphthalmia to social integration issues because of their facial malformation and their associated partial or complete blindness. ${ }^{16}$

\section{Conclusion}

Anophthalmia and severe microphthalmia pose significant prenatal diagnosis problems in Sub-Saharan Africa. Diagnoses and medical management of these conditions remain complex and expensive for poverty-stricken people. Further skills training of medical specialists and adequate technical facilities for prenatal diagnosis would constitute the essential means for early diagnosis, in an effort to reduce negative social effects for the patient.

\section{Disclosure}

The authors report no conflicts of interest in this work.

\section{References}

1. Araujo Júnior E, Kawanami TE, Nardozza LM, Milani HJ, Oliveira PS, Moron AF. Prenatal diagnosis of bilateral anophthalmia by 3D "reverse face" view ultrasound and magnetic resonance imaging. Taiwan J Obstet Gynecol. 2012;51(4):616-619.

2. Mouriaux F, Audo I, Defoort-Dhellemme S, et al. Anophtalmies congénitales [Management of congenital microphthalmos and anophthalmos]. $J$ Fr Ophtalmol. 1997;20(8):583-591. French.

3. Verma AS, Fitzpatrick DR. Anophthalmia and microphthalmia. Orphanet J Rare Dis. 2007;26(2):47-51.

4. Fantes JA, Ragge NK, Lynch SA, et al. Mutations in SOX2 cause anophthalmia. Nat Genet. 2003;33(4):461-463.

5. Stoll C, Dott B, Alembik Y, Roth MP. Associated malformations among infants with anophthalmia and microphthalmia. Birth Defects Res A Clin Mol Teratol. 2012;94(3):147-152.
6. Stricker M, Gola R. L'anophtalmie congénitale Chirurgie plastique et réparatrice des paupières et de leurs annexes. [Congenital anophthalmia plastic and reconstructive surgery of the eyelids and their annexes] Journal Français d'Ophtalmologie. 1990;22(9):177-191.

7. Roth P, Roth A, Riethmuller D, et al. Ophtalmologie fotale: l'utilité de l'examen des yeux au cours de l'échographie anténatale. [Fetal Ophthalmology: the usefulness of the eye examination during antenatal ultrasound]. Ophthalmology. 1997;11:85-96.

8. Venditteli F, Janky E. Suivi Clinique et Paraclinique d'une grossesse normale [Clinical and paraclinical monitoring of a normal pregnancy]. J Gynecol Obstet Biol Reprod (Paris). 2001;30(1):51-58. French.

9. Achiron R, Gottlieb Z, Yaron Y, et al. The development of the fetal eye: in utero ultrasonographic measurements of the vitreous and lens. Prenat Diagn. 1995;15(2):155-160.

10. Chen CP, Wang KG, Huang JK, et al. Prenatal diagnosis of otocephaly with microphthalmia/anophthalmia using ultrasound and magnetic resonance imaging. Ultrasound Obstet Gynecol. 2003;22(2):214-215.

11. Dufit C, Baggio E, Ruban JM, Buenerd A, Hermier M. L'anophtalmie foetale: Problème du diagnostic anténatal: à propos d'un cas [Fetal anophthalmos. Problem of the prenatal diagnosis: a case report]. J Fr Ophtalmol. 1999;22(9):966-969.

12. Wong HS, Parker S, Tait J, Pringle KC. Antenatal diagnosis of anophthalmia with 3D ultrasound: a novel application of the reverse face view. Ultrasound Obstet Gynecol. 2008;32(1):103-105.

13. Schittkowski MP, Guthoff RF. Injectable self inflating hydrogel pellet expanders for the treatment of orbital volume deficiency in congenital microphthalmos: preliminary results with a new therapeutic approach. Br J Ophthalmol. 2006;90(9):1173-1177.

14. Adon KP. L'assurance maladie universelle en Côte d'Ivoire: entre protection sociale et politique de santé. [Universal health insurance in Ivory Coast: from social welfare and health policy]. Médecine d'Afrique Noire. 2013;6002:71-82.

15. Robson CD, Barnewolt CE. MR imaging of fetal head and neck anomalies. Neuroimaging Clin N Am. 2004;14(2):273-291.

16. Diomande IA, Diomande GF, Bile PEFK, et al. mutilating surgery and indications in ophthalmology Rev. col. odonto- stomatol. Afr. Chir. Maxillo-fac. 2013;20(3):53-58.
International Medical Case Reports Journal

\section{Publish your work in this journal}

The International Medical Case Reports Journal is an international, peer-reviewed open-access journal publishing original case reports from all medical specialties. Previously unpublished medical posters are also accepted relating to any area of clinical or preclinical science. Submissions should not normally exceed 2,000 words or

\section{Dovepress}

4 published pages including figures, diagrams and references. The manuscript management system is completely online and includes a very quick and fair peer-review system, which is all easy to use. Visit $\mathrm{http}: / /$ www.dovepress.com/testimonials.php to read real quotes from published authors. 